\title{
An Overview of the Literature Related to Social Representations Published in Scientific Journals
}

\author{
João Wachelke ${ }^{1}$ \\ Fabíola Rodrigues Matos \\ Gustavo Cerchi Soares Ferreira \\ Rafaela Rannelle de Lima Costa \\ Universidade Federal de Uberlândia, Uberlândia, MG, Brazil
}

\begin{abstract}
The present study aims at characterizing part of the academic production on social representations published in scientific journals, so as to provide information about the development and current state of the field. In August and September 20132526 abstracts of papers published in journals indexed in four databases were retrieved, all of which were about social representations. For each abstract registers were made concerning the country in which the first author's institution was located, publication year, journal discipline and categorized information relative to the studied group and social objects. The results confirmed and expanded previously conducted meta-analyses, giving evidence of a contrast between applied studies in the health area involving related groups and objects, more typical from South America and Brazil, and psychosocial research linked to the psychology field and carried out mostly by European researchers. A considerable increase in the importance of the participation of Brazilian and South American authors relative to the total production was also noticed, replacing authors from European institutions as leaders according to that criterion.
\end{abstract}

Keywords: Social representations, scientific production, bibliographic research, Bibliometrics.

\section{Um Panorama da Literatura Relacionada às Representações Sociais Publicada em Periódicos Científicos}

\section{Resumo}

O presente estudo visa a caracterizar parte da produção acadêmica sobre representações sociais publicada em periódicos científicos, de modo a fornecer informações sobre o desenvolvimento e estado atual do campo. Em agosto e setembro de 2013 foram obtidos 2526 resumos de artigos publicados em periódicos indexados em quatro bases de dados, todos sobre representações sociais. Para cada resumo foram registrados o país da instituição do primeiro autor, ano de publicação, disciplina do periódico e informações categorizadas relativas aos grupos e objetos sociais estudados. Os resultados confirmaram e expandiram meta-análises realizadas anteriormente, evidenciando uma contraposição entre estudos aplicados na área de saúde com grupos e objetos relacionados, mais típicos da América do Sul e Brasil e pesquisas psicossociais ligadas à área da psicologia e realizadas por pesquisadores principalmente do continente

1 Mailing address: Instituto de Psicologia, Universidade Federal de Uberlândia, Campus Umuarama, Bloco 2C, Sala 19, Av. Pará 1720, Bairro Umuarama, Uberlândia, MG, Brazil 38400-902. Fone: +55.34.3218-2822. E-mail: wachelke@yahoo.com

Financial support: Conselho Nacional de Pesquisa e Desenvolvimento Tecnológico (CNPq), Fundação de Apoio à Pesquisa de Minas Gerais (FAPEMIG) and Pró-Reitoria de Pesquisa e Pós-Graduação da Universidade Federal de Uberlândia (PROPP-UFU). 
europeu. Nota-se também um aumento de importância considerável na participação de primeiros autores brasileiros e sul-americanos em relação ao total, tornando-se líder no volume de produção acadêmica na área, substituindo autores provenientes de instituições europeias.

Palavras-chave: Representações sociais, produção científica, pesquisa bibliográfica, Bibliometria.

\section{Una Visión General de la Literatura Relacionada con las Representaciones Sociales Publicadas en Revistas Científicas}

\section{Resumen}

El presente estudio tiene como objetivo caracterizar parte de la producción académica sobre las representaciones sociales publicada en revistas científicas, para proporcionar información sobre el desarrollo y el estado actual del campo. En agosto y septiembre de 2013, fueron recuperados 2526 resúmenes de artículos publicados en revistas indexadas en cuatro bases de datos, todos sobre las representaciones sociales. Para cada uno se hicieron registros sobre el país de la institución del primer autor, año de publicación, la disciplina de la revista y los grupos y objetos estudiados. Los resultados confirmaron y ampliaron meta-análisis realizados antes, e muestran un contraste entre estudios aplicados en el área de la salud con grupo y objetos afines, más típicos de América del Sur y Brasil, e investigaciones psicosociales del campo de la psicología llevados a cabo por investigadores europeos. Se observó también un aumento considerable en la importancia de la participación de autores de Brasil y de América del Sur en relación con la producción total, en sustitución de autores de instituciones europeas como líderes de acuerdo a ese criterio.

Palabras clave: Representaciones sociales, producción científica, investigación bibliográfica, Bibliometría.

This paper presents an overview of part of the worldwide academic production related to social representations published in scientific journals until mid 2013. Social representations are common sense theories shared and elaborated by groups about everyday issues (Jodelet, 1989; Moscovici, 1984). The expression social representation is usually associated with social representations theory, a research paradigm from social psychology that originated from Serge Moscovici's (1976) doctoral thesis on the shared beliefs of the French population about psychoanalysis in the 50s.

Various decades after the proposition of the theory, a study of the characteristics of papers employing social representations may provide an evaluation of the international development of the theory and its popularization across different disciplines throughout the years. Other than the scientific qualities of a theory (i.e. the tests that it faces continuously in order to prove itself a plausible model to understand social reality), its diffusion amongst disciplines, countries and continents might provide evidence of its value as a framework to tackle scientific problems and shed light into the needs of the academic communities of different contexts.

Amongst the various social psychological schools, social representations theory is commonly considered a sociological form of social psychology (Farr, 1998; Moscovici, 1989). Its specificity lies in the attention given to historic and communication processes in the construction and transmission of everyday knowledge (Jodelet, 1989; Rouquette, 1998), which differentiates it from mainstream social psychology varieties, more focused on cognitive processes (De Rosa, 1993; Duveen \& De Rosa, 1992).

A variety of social representations schools and perspectives can be found, stressing different aspects of the phenomenon, ranging from ethnographic approaches to understand the relationship between individual appropriation of group culture to experimental studies of the individual management of information that is shared by group members (for works illustrat- 
ing the methodological diversity of social representations research, see Abric, 2003; Moreira, Camargo, Jesuíno, \& Nóbrega, 2005).

It is a perspective that is often open to interdisciplinary dialogue. Much of the research is dedicated to applied transdisciplinary themes such as health and education (Jodelet, 2011). Moreover, the social representations concept is an effort to trespass the social psychological borders of phenomena to attain more social levels of explanation, attracting the attention of scholars from the other social sciences. It must also be reminded that representation is a concept that is popular in those fields independently of its use in the context of Moscovici's paradigm; the latter was actually inspired by Durkheim's (1898) notion of collective representation. So regardless of important differences, considerable overlap is expected as the various notions of representation from social science models fulfill similar roles in the theoretical systems.

Originally a social psychological theory from France, social representations theory was well received by some researchers from European countries like Portugal, Italy and England. Authors who classify the varieties of social psychology that are proposed around the world associate the theory with European social psychology, due to its emphasis on ideological and intergroup processes (Farr, 1993; Jesuíno, 2000). It later spread to other continents, finding particular success in Latin American countries and French-speaking Canada. Its popularization was much more modest in the United States, possibly due to a preference for an individualistic and experimental cognitive social psychology, which contrasts with the comparative study of historic, shared and culturally elaborated social representations (Farr, 1996).

The assessment of the state of art of social representations research can provide information concerning the contexts of diffusion of the study of related phenomena and the aspects that are privileged. There are some well-known examples of such efforts in the literature. A first project in that direction was possibly the general bibliography in social representations organized by Jodelet and Ohana (1989), published in a classical book of the field. The bibliography was just a list of resources that were aligned with social representations theory up to that time.

Some well known meta-analyses of the literature on social representations have been provided by Annamaria de Rosa. In 1992, she reviewed the growing literature on developmental psychology aligned with social representations and social cognition and discussed their points of contact and divergence, including a categorization of studied social objects or thematic perspectives took into account by the research (De Rosa, 1992).

De Rosa and D'Ambrosio (2008) have carried out a meta-analysis of 1731 abstracts presented in English, French and Spanish in the first eight International Conferences on Social Representations, the main biannual conferences related to social representations theory. Other than coding classic bibliographic information such as the conference in which each paper was presented and the nationality of the first author, they categorized each abstract in terms of the thematic areas privileged by the investigation or the type of treatment given to social representations theory. Concerning the latter category, the authors assessed whether just a general treatment was given to the phenomenon of social representations, or if specific theory-related paradigms were focused - such as structure, genesis, or meta-theory. The results indicated a contrast between papers authored by Europeans, which focused proportionally more on theoretical aspects and references related to paradigmatic social representations theory, and papers written by Latin Americans, which had an applied and empirical nature and dealt with social representations in a generic way.

In the same vein, Madiot (2013) presented an analysis of the French language abstracts of the 11 biannual International Conferences on social representations. Her corpus consisted in 2549 abstracts. Her analysis also focused on the theoretical schools that were identified in the communications and methodological choices. Concerning social representation objects, the most frequent ones were work, education and health. In terms of groups, the populations of 
children, parents, teachers, caretakers and health professionals were privileged.

More recently, De Rosa (2013) presented an overview of the meta-theoretical analysis of an extensive body of literature on social representations theory. In January 2012, the database consisted of 6938 references, 2700 of which were articles and book chapters that underwent detailed meta-analysis. She presented the results of a meta-theoretical analysis based on 2065 bibliographical sources, including 956 book chapters, 936 journal articles, 65 papers presented at conferences, $57 \mathrm{PhD}$ thesis chapters, 46 university reports or manuscripts and 5 web documents, all published from 1952 to 2009 . Her results point out a trend to publish theoretical contributions in book chapters and empirical research in journal articles, and also confirm the interdisciplinary interest revolving around social representations theory. Amongst the main topics of the published contributions, the analysis identified theoretical and methodological issues, the relationship of social representations theory with social psychology and other disciplines, health-illness, communication, and interpersonal and intergroup relationships. The research is concerned with assessing the specific aspects of social representations theory that are stressed by the papers. The project differentiates between studies that incorporate the theoretical concepts of social representations theory and others that refer to the phenomenon in a generic way, possibly disconnected with the theory.

There have also been some analyses of the social representations literature provided by Brazilian scholars. The first social representations studies in Brazil were published from 1982 to 1997 (Sá \& Arruda, 2000). Arruda (1987) published a first review of the pioneer works related to the theory or the phenomenon of social representations in the Northeast of Brazil in the period preceding the Jornadas Internacionais sobre Representações Sociais (JIRS). Sá and Arruda (2000) analyzed 867 scientific works encompassing papers, theses, dissertations and abstracts published between 1988 and 1987; they concluded that the volume of production was growing fast at the time, with the expansion of book publishing. As the JIRS became consolidated, some reviews emphasized the methodological assessment of the published abstracts. Those analyzes brought to light the applied nature of the Brazilian production, with special attention to health and education issues (Arruda, 2005; Camargo, Wachelke, \& Aguiar, 2007; Jodelet, 2011). The interdisciplinary interest in the study of social representations is also evident from the existence of reviews of graduate level dissertations and theses aligned with the theory in the fields of Nursing (A. M. F. Silva, Martini, \& Becker, 2011; S. E. D. Silva, Camargo, \& Padilha, 2011) and Education (Sousa, 2002).

It can thus be noticed that social representations theory scholars are constantly monitoring the literature aligned with their paradigm in order to map differences and transformations in scientific practices regarding the theory. However, social representation is an expression that can lead to relevant research and theory outside the framework proposed by Moscovici, in basic and applied fields. The study of social representations in a way not directly linked to social representations theory is not a problem, as anthropologists, sociologists and other scholars can legitimately investigate symbolic constructions, their consequences and determinations with other guidelines. We propose an overview of the research about the construct of social representations in all social sciences, regardless of theoretical divergences.

In addition, we shall focus our attention on a specific bibliographic source: peer-reviewed journals. Such choice is justified by the thorough evaluation that each manuscript undergoes in the process managed by an editor and usually two reviewers, belonging either to the editorial board or having ad hoc status. Papers are only accepted after their relevance and correction are ensured through quality control, in a process that is usually stricter -or at least more uniform, sharing standards- than what is observed sometimes with books or conference proceedings. We propose that there is space for a thematic analysis of journal papers on social representations in a broader set of international sources than what was hith- 
erto observed.

Other than classical variables like the location of first authors' institutions or the discipline affiliation of journals, emphasis will be given to the identification of the populations and groups taken in consideration in social representations studies. Every social representation study necessarily refers to a group that represents and to an object, a social life topic with some salience to the group, that is represented (Jodelet, 1989). There is a significant variety of population and objects studied by social representations studies.

An analysis of the groups and objects that inspire more studies and the association of those choices with specific institutional and geographic contexts can shed light into the research practices related to social representations. Similar analyses have been carried out, usually through a categorization of broad thematic areas (Camargo et al., 2007; De Rosa, 2013; De Rosa \& D’Ambrosio, 2008). De Rosa (2013) pointed out that each thematic area, such as health-illness or economics-work-organization, comprises several subtopics. The latter can usually be translated into objects or object categories. In contrast, Madiot (2013) presented a frequency distribution directly at the level of social object classes, but did not verify any associations with other variables, restricting her investigation a little.

The aim of the present contribution is to carry out an exploratory thematic analysis of the abstracts of journal articles related to the study of social representations. Articles from international databases relative to psychological, social and health sciences were included, and the considered variables concern the geographical context of the first author, the disciplines linked to the journals, publication periods and the groups and objects that were studied.

\section{Method}

\section{Data Sources}

A documental study was carried out. We retrieved all abstracts in English from four major abstract databases that resulted from a search with the terms "social representation" or "social representations" in the title, abstract and keywords fields. Although the choice of databases was based on some diversity of disciplines and regions and took into account important resources, it must be clear that the effort does not reflect the full universe of scientific databases. The chosen databases were PsycINFO (American Psychological Association); Scientific Electronic Library Online (Scielo.org); MEDLINE Complete (EBSCOHost); and Sociological Abstracts (ProQuest). The choices were justified by the coverage of important disciplines and geographic areas, including one database per main discipline field that is commonly associated with the study of social representations (psychology, social sciences, health) and also a general data base comprising Latin American journals of all fields, providing significant overlap with discipline-specific bases but at the same time adding some more recent or more regional journals. PsycINFO is the main psychology database and also includes journals from other human and health sciences, Scielo is a generalist database that covers mostly South American journals - but also includes South Africa and the Iberian countries -, Sociological Abstracts covers the social sciences and MEDLINE contains research related to the health field.

\section{Procedure}

Abstract search and coding took place from August to September 2013. The contents of abstracts were checked, so that only the ones related to social representation in the sense of shared knowledge were kept for analysis. Abstracts that were related to other meanings of the social representation expression (e.g. political participation or popular representativeness, were excluded). Moreover, since the content of the selected databases overlaps, repetitions were also excluded. A total of 3359 abstracts were identified at first, 2526 of which were unique cases related to the referred meaning of social representations. Those 2526 abstracts formed the sample retained for analysis. The co-authors carried out article search and retrieval activities independently and the first author checked and discussed their results in order to reach a consensus in terms of 
which research units should or should not be included.

Information related to each abstract was coded in a dataset for further analysis. The following information was registered: year of publication, discipline of the journal in which the abstract was published, country of the first author, studied social object and studied social group.

The information relative to groups and objects was categorized according to its content, grouping similar themes in broader categories. In total, 23 categories were formulated to account for objects and 16 for groups. In order to test the category systems, two coders, both of them authors of the present manuscript, categorized 191 abstracts $(7.5 \%$ of the total) independently both for group and objects. The proportion of inter-rater agreement was $79 \%$ for objects and $88.5 \%$ for groups. Adjustments were made to the system to solve ambiguous categorizations. Later on, one of the coders proceeded to categorize groups and the other was responsible for the categorization of objects. The first author was responsible for checking the categorization and discussing ambiguous cases to decide their appropriate categories.

The twenty-three categories relative to social objects (examples in parentheses) were: citizenship and human rights (Human Rights, citizenship); competences and skills (teacher's skills, intelligence); culture and ethnicity (Greek culture, Buddhism); human development (adolescence, human conception); drugs (tobacco consumption, cocaine); education (school environment, graduate courses); emotions (fear, happiness); historic events (European colonization, 2008 economic crisis); racial group (black people, racial prejudice); environment (water, environment); controversies and everyday events (work accidents; urbanism); social position (homeless people, minorities); work (work conditions, professional autonomy); health and wellbeing (AIDS, quality of life); economic issues (poverty, trade); political issues (democracy, collective action); social relations (friendship, marital life); sexuality and gender (body, sexual options); technology (internet, reproduc- tion technologies); territory and community (groups linked to living or being born in specific regions), violence and crime (aggression, harassment); others (objects with low frequencies not fitting the other categories); absent (abstracts in which objects are not applicable - e.g. in a general theoretical essay - or not informed).

The sixteen categories of groups were: clients or consumers; cultural comparisons (studies with groups of people with different nationalities); students (university and school students); ethnic groups; family members; groups associated with social positions (high, low class); groups associated with preferences, tastes or habits (e.g. smokers, sport practitioners); age groups; region residents or groups linked to territory (e.g. inhabitants of a specific neighborhood); multicategory (consideration of two or more category memberships at the same time); general population (no specification other than sex of group members); patients and bearers of chronic illness; professionals with specific educational formation (e.g. education and health professionals); general workers and employees; others (groups with low frequencies not fitting the other categories); absent (abstracts in which groups are not applicable - e.g. in documental research - or not informed).

\section{Results}

\section{Publication Period and First Author Location}

Concerning the relationship between publication period and the continent of affiliation of the first author, the year of publication variable was recoded into decade of publication, resulting in five modalities: 60 s and 70 s (jointly accounting for only 13 abstracts), the $80 \mathrm{~s}, 90 \mathrm{~s}$, 2000s and 2010 - mid 2013. In the 60s and 70s, 12 of the 13 abstracts had the first author affiliated to a European university. Through the $80 \mathrm{~s}$ $(n=92)$ and $90 \mathrm{~s}(n=454)$ the predominance of "European" first authors continued, with $84.8 \%$ and $66.3 \%$, but displaying a clear emergence of authors located in North America $8.7 \%$ in the $80 \mathrm{~s}$ and $10.3 \%$ in the $90 \mathrm{~s}$ ) and a more important 
growth in South America (5.4\% in the $80 \mathrm{~s}$ and $18 \%$ in the $90 \mathrm{~s}$ ).

From the 2000s onwards, abstracts led by researchers from South American institutions take the lead. In the years $2000(n=1285)$, first authors from South America correspond to $45.4 \%$ of the total, while their proportion is of more than half $(55.8 \%)$ of the 682 published abstracts in the 2010-2013 period. The decrease in the proportion of studies led by Europe-based researchers continues $(39.7 \%$ in the $2000 \mathrm{~s}, 32.4 \%$ in 2010-2013). The proportion of abstracts with authors from North America is stable $(9.2 \%$ in the $2000 \mathrm{~s}, 9.5 \%$ in $2010-2013$ ).

At the country level, first authors from the United Kingdom published the larger proportion of studies in the $80 \mathrm{~s}(25 \%)$, followed by authors from France (20.7\%) and Italy (13\%). First authors from Brazil were responsible for only 3.2\% of the published studies of that decade.

The pattern was gradually inverted. In the 90s, first authors from France were responsible for $16.3 \%$ of the abstracts, followed by the United Kingdom (15.6\%) and Brazil (13.2\%). In the $90 \mathrm{~s}$, first authors from Brazilian institutions took the lead with $34.6 \%$ of the published studies, whereas first authors from France and the United Kingdom only corresponded to $12.4 \%$ and $7.1 \%$ of the abstracts. In the period of 2010-2013, the difference in proportion grew more: the first authors from Brazil published $39.4 \%$ of the studies, whereas French ones were responsible for 10.7\%. Authors from Argentina published 6.4\% of the abstracts in the period, and British ones did $6.1 \%$

In all the other continents, the proportion never surpasses $2.4 \%$ in any studied period, and currently they are less than one percent for the most recent period. For authors from Oceania, there were no published abstracts in the $60 \mathrm{~s}$ and $70 \mathrm{~s}$ nor the $80 \mathrm{~s}$. The proportions for the 90 s were $2.4 \%, 1.9 \%$ for the 2000 s and $.8 \%$ for 2010-2013. The results relative to Asia were similar: nothing up to the $80 \mathrm{~s}$, and then $1.5 \%$ for the $90 \mathrm{~s}, 2.4 \%$ in the $2000 \mathrm{~s}$ and $.4 \%$ in 2010 2013. Regarding first authors linked to African institutions, the first abstracts were published in the $90 \mathrm{~s}(1.3 \%)$, and then there were $.9 \%$ in the
2000 s and $.4 \%$ in $2010-2013$. Finally, four abstracts led by an author from Central America was published in the 2000s, three in 2010-2013 and one in the $80 \mathrm{~s}$.

\section{First Author Location and Journal Discipline}

The larger proportion of research related to social representations was published in psychology journals in all continents. In terms of abstracts that had European first authors $(n=$ $1123), 66.7 \%$ of the studies were published in journals of the field, followed by social sciences (8.7\%) and health $(5.6 \%)$ journals. The clear predominance of psychology was also observed in contributions of authors from continents with a smaller number of abstracts: Oceania $(n=42)$ had $73.8 \%$, while Asia $(n=41)$ had $70.7 \%$.

The distribution of studies with North and South American first authors was not so contrasting. Regarding South American abstracts ( $n=1052), 30.7 \%$ of the studies were published in psychology journals, $18.4 \%$ were retrieved from interdisciplinary health journals, $17.6 \%$ appeared in nursing journals, $8.2 \%$ in social sciences publications and $7.1 \%$ in education journals. As for North American abstracts $(n=239)$, $23.8 \%$ were from psychology journals, $18.4 \%$ from health journals, $15.4 \%$ from the social sciences, $10.4 \%$ from sociology-specific journals and $6.6 \%$ were published in education journals.

The distributions of disciplines relative to abstracts with African and Central American first authors were more scattered. Concerning the African abstracts $(n=21), 8$ were from psychology journals, 4 from health, 4 from social sciences and 2 from medicine. Finally, 2 of the 8 Central American abstracts were from psychology and two from medicine journals.

At the country level, the two predominant locations of the first authors were Brazil ( $n=$ $776)$ and France $(n=334)$. The distribution of abstracts from authors located in France show a clear predominance of the space of psychology journals $(69.4 \%)$, followed by sociology (7.7\%), social sciences in general $(6.5 \%)$ and health (5\%). In Brazil, the distribution is more homogeneous among the top fields. Psychology 
journals lead with $32 \%$, while nursing follows with $23 \%$, health has $20.6 \%$ and education $6.5 \%$. Psychology journals have a clear predominance in abstracts from British first authors (total $n=$ 229 ; proportion of papers in psychology journals: $64.6 \%)$, as well as studies from Italian $(n=$ 124, psychology: 79.8\%), Spanish $(n=92$; psychology: $63 \%)$ and Portuguese $(n=84$, psychology: $71.4 \%$ ) authors. The following countries in frequency have a different profile. The higher proportion of abstracts from first authors located in Colombia $(n=84)$ were from health journals $(28.5 \%)$, and the same was observed for Mexican authors ( $n=86$, health: $23.2 \%$ ).

\section{First Author Location, Journal Discipline and Proportions of Studied Objects and Groups}

It must be noted that of the 2526 retrieved abstracts, $848(33.6 \%)$ did not present information regarding a specific social group, either due to them being general essays or to the absence of such information. The analyses relative to the studied social groups dealt only with the cases with identifiable group categories $(n=1678$ or $66.4 \%$ overall). Concerning social objects, 515 abstracts $(20.4 \%)$ did not present identifiable information, meaning that the analyzed abstracts comprised a total of 2011 , or $79.6 \%$ of the total. This means that in the following analyses, $100 \%$ in terms of studied social groups add up to 1678 abstracts, and $100 \%$ for social groups represents 2011.

Table 1 presents two separate pieces of information: the percentage distributions of the studied social objects and groups in the abstracts, organized according to location of the first author's institution. Only the continents, countries, object and group categories with higher frequencies are displayed. Relative to each presented continent or country, a cumulative proportion column indicates how many of the abstracts are observed in the table. A final row (Overall) features the distribution in the whole sample of abstracts.

Concerning objects, the most remarkable pattern involves the clear predominance of stud- ies dealing with health issues. Work is the second most salient issue, but it is only present in little more than six percent of the abstracts. For the three continents in the table, health and well being is the privileged category, with a more pronounced profile in abstracts from authors located in South America. Regarding authors situated in specific countries, the ones from Brazil show a differentiated profile in terms of a preference to health and well-being objects. Abstracts from Colombian, British, Mexican, Portuguese and Argentine authors are also concentrated around health and well being, but some salient themes can be observed in such countries: violence and crime (United Kingdom, Colombia), sexuality and gender (Mexico, Portugal), work (Argentina). In contrast, the remaining countries have more balanced and varied abstract distributions in terms of object categories.

The predominance of health studies in South America and Brazil is also reflected in the investigated social groups. It can be observed that studies from authors located in Brazil give preference to the study of groups of professionals with specific formations, like doctors, teachers and nurses, followed by students of all kinds and medical patients. In European and North American studies, studies with student populations prevail, possibly linked to education issues or basic theory testing, since such populations are more accessible. Abstracts from British, Spanish and Colombian authors have high proportions of general population studies as well.

Table 2 presents the profiles of the studied social objects and groups per journal discipline. Looking simultaneously at the two sides of the table, three profiles clearly emerge. Abstracts published in health journals (including health interdisciplinary journals, medicine and nursing) privilege the study of groups of professionals and/or patients, and clearly focus on health and well being-related objects. Abstracts from other social and human sciences (psychology, sociology, social sciences in general) also have an important proportion of studies focusing on health-related issues, but tend to study groups of students (psychology and social sciences) or the general population (sociology). Abstracts 


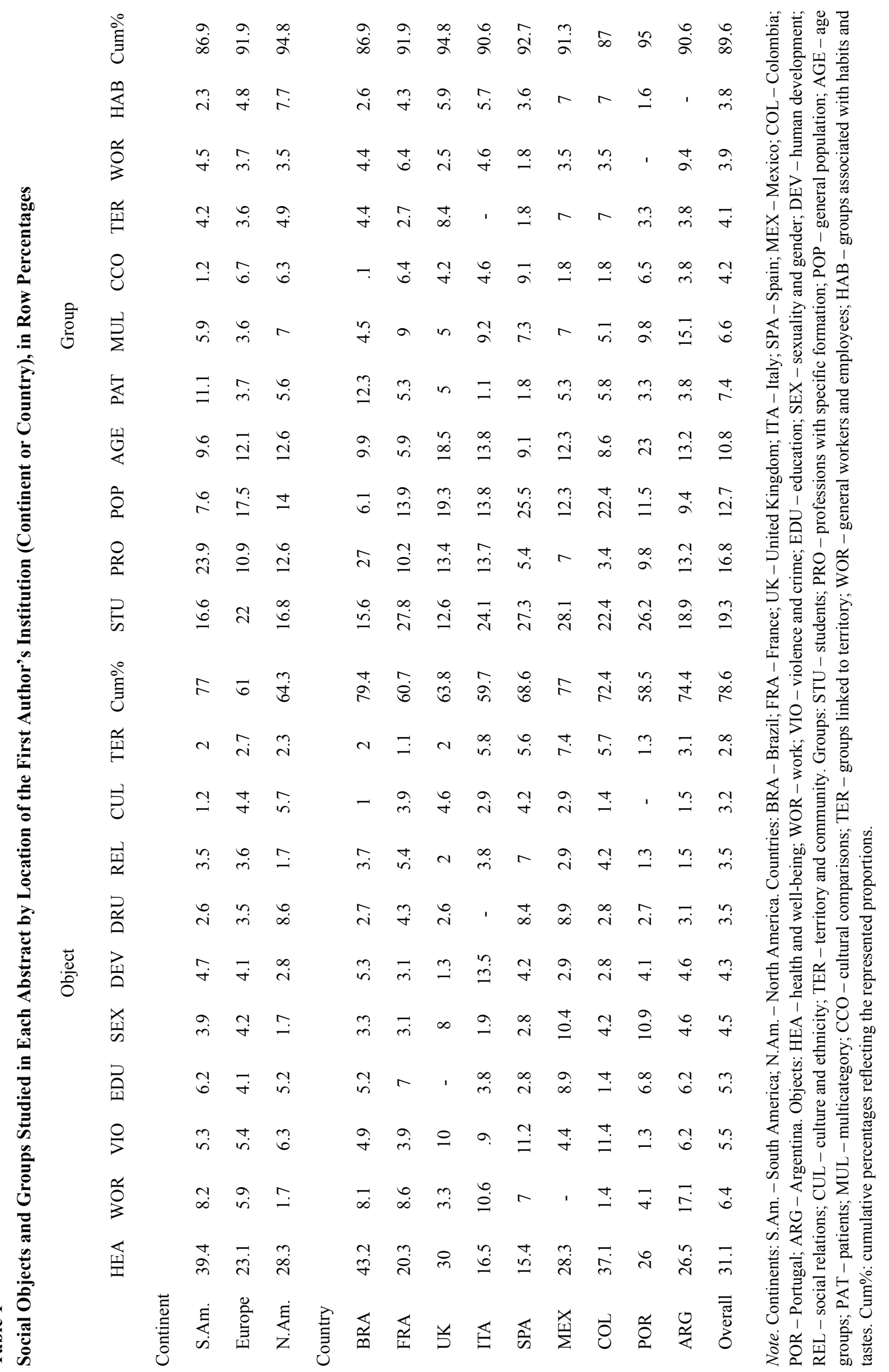




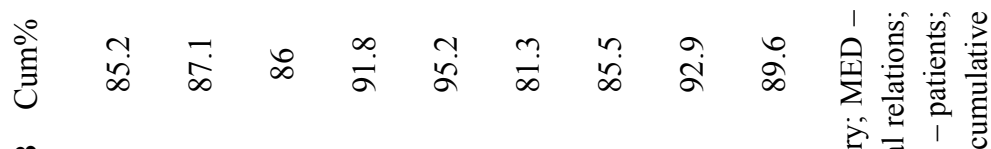

空 $\vec{i}$ in

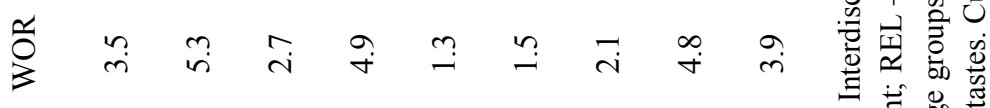

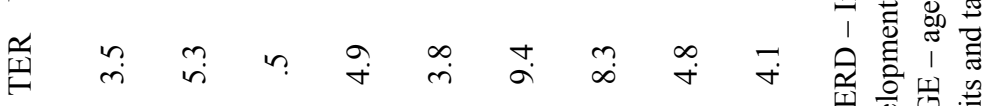

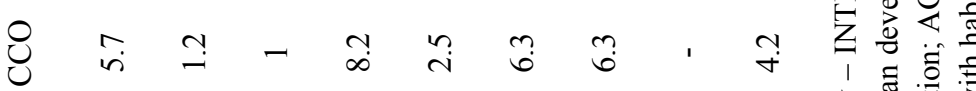

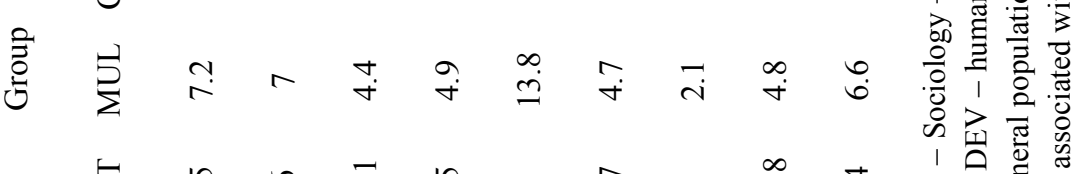

空

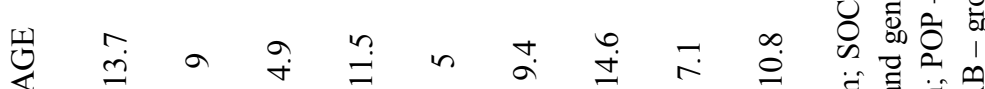

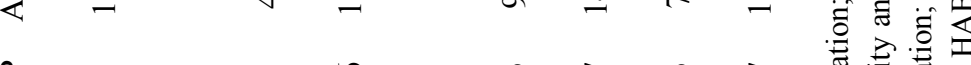

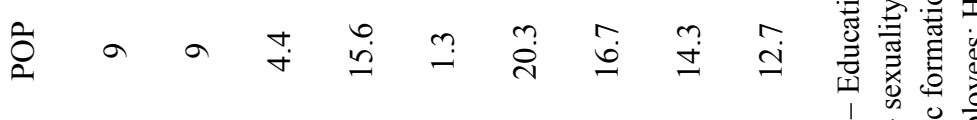

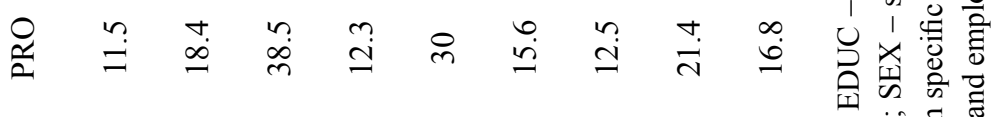

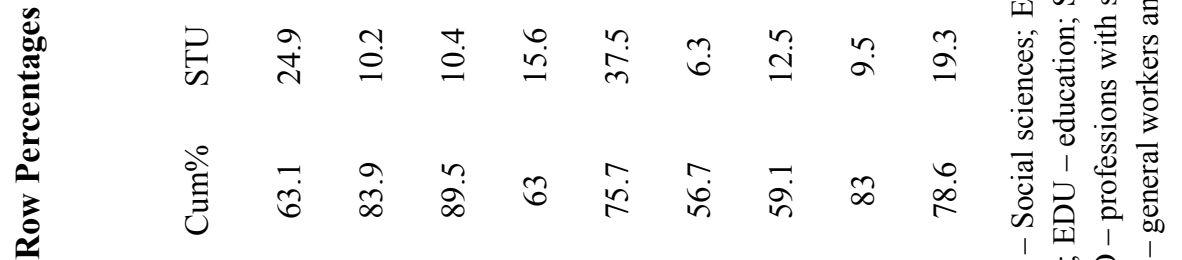

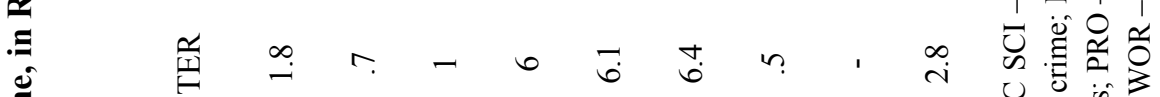

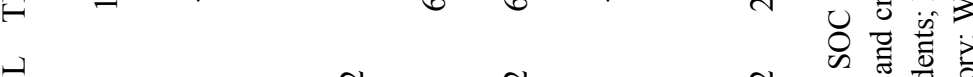

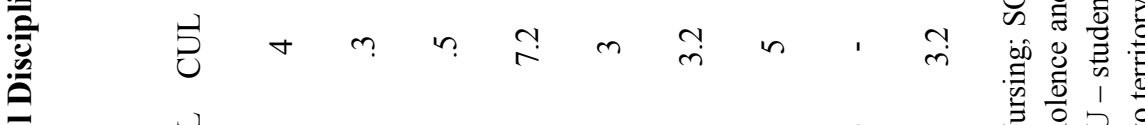

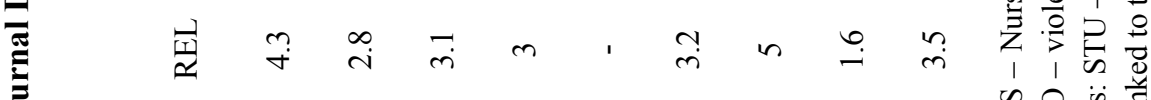

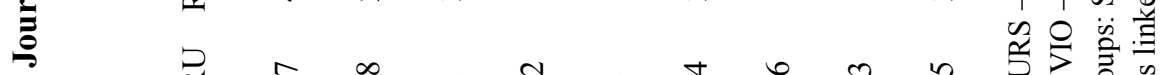

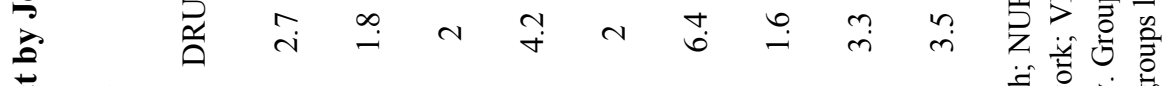

比

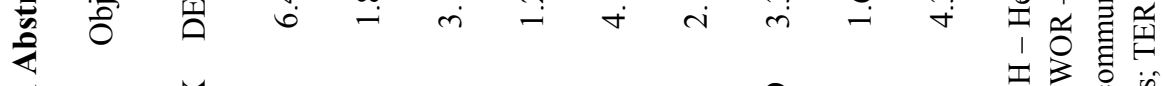

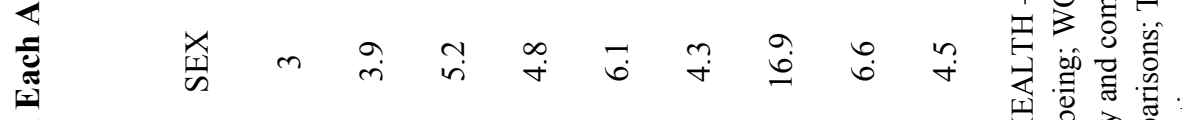

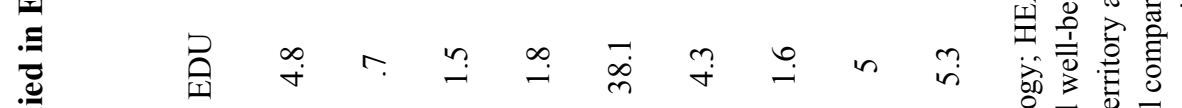

焉

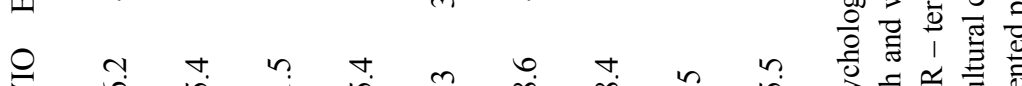

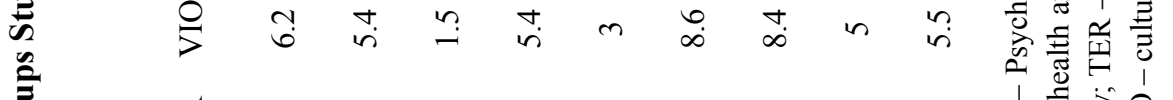

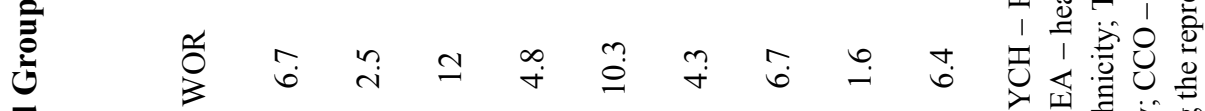

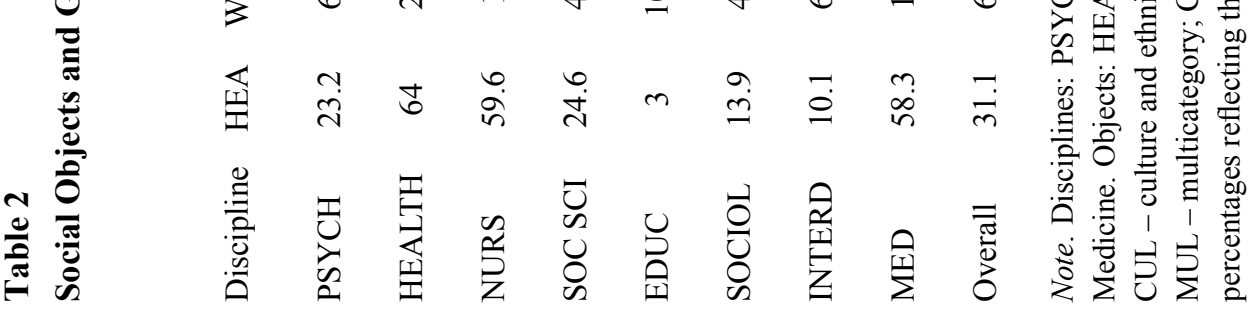


published in education journals deal mostly with education-related objects and students and teachers samples. Abstracts from general interdisciplinary journals possess a more diverse profile both in terms of groups and objects.

In order to have a comprehensive understanding of the main dimensions of association, a multiple correspondence analysis was carried out. Multiple correspondence analysis is a descriptive technique that summarizes an individuals (rows) $\times$ variables (columns) matrix in a decomposition of a smaller number of factors; each factor describes oppositions in terms of different individual or variable profiles. The first factor is the most important one, explaining the larger portion of inertia (the term employed to refer to variance), followed by the second, third, and so on. Factors can be geometrically represented in maps in which specific points (variable or individual profiles) can be plotted, making it possible to grasp the structure of the data (Greenacre, 2007; Husson, Lê, \& Pagès, 2011). In the present case, the statistical individuals, or cases, were the abstracts, and the active variables were group and object categories. To help with the interpretation of the axes, some supplementary variables relative to the abstracts (which do not participate in the calculation of the analysis) were projected in the map: the continent in which the first author's institution was located, publication decade and journal discipline. The analysis was conducted with the $\mathrm{R}$ software $(\mathrm{R}$ Core Team, 2013) and the GDAtools package (Robette, 2014). Only group and object categories with frequencies higher than $1 \%$ were included as active in the analyses. In addition, "others" categories were also set as supplementary, due to the difficulty to interpret them.

We shall analyze the first factorial plane, which includes the two most important factors. The first factor had an eigenvalue of .71 , accounting for $4.68 \%$ of the total inertia. The second factor, with an eigenvalue of .66, represented $4.36 \%$ of the inertia. Both factors together account for $9.03 \%$ of the inertia. Due to the large number of dimensions included in multiple correspondence analysis, the inertia rates of the axes are usually low and do not reflect well their importance. Jean-Paul Benzécri proposed an alternative way to calculate the inertia to better appreciate the importance of the first axes, prioritizing larger-than-average eigenvalues (Le Roux \& Rouanet, 2010, pp. 3940). According to the modified calculation, the first factor explains $28.6 \%$ of the inertia and the second is responsible for $16.6 \%$; both of them together account for $45.2 \%$ of the total inertia.

Figure 1 displays the map relative to the first two factors of the multiple correspondence analysis. The active categories that are displayed have significant contributions to the factor that are higher than the average (100/33 active categories $=3.03)$. The displayed supplementary categories all have values higher than 3.29 or lower than -3.29, which indicate a strict significant cut-off point $(p=.001)$ in the values-test presented by Lebart, Morineau and Piron (1997). In Figure 1, an underline sign (“")" next to a category label indicates that the factor contribution to factor 1 is higher than the average, just as a vertical bar ("|") signals an important contribution to factor 2. A plus sign ("+") indicates higher-than average contributions in both factors.

The distribution of the points in the cloud of individuals (not shown) is very similar from the points relative to the active categories in Figure 1. It reveals a pattern that is called horseshoe effect, which can be interpreted as a dominance of the first factor, i.e., most of the relevant information in terms of opposition is presented in the first factor. The second factor then opposes extreme profiles from the first factor to other intermediate profiles, and following factors keep refining the interpretation of the first factor but reflect the same phenomenon (Lebart et al., 1997). The second dimension, though, has some relevance as it complements the pervasive contrast of the first factor (Greenacre, 2006).

It can be observed that the main contrast in terms of research profiles present in the abstracts is the one of basic sociopsychological and social research, situated on the positive coordinates of factor 1, and applied health-related research on the negative side. The objects of interest on the part of social researchers involve a higherthan average proportion of territory and com- 


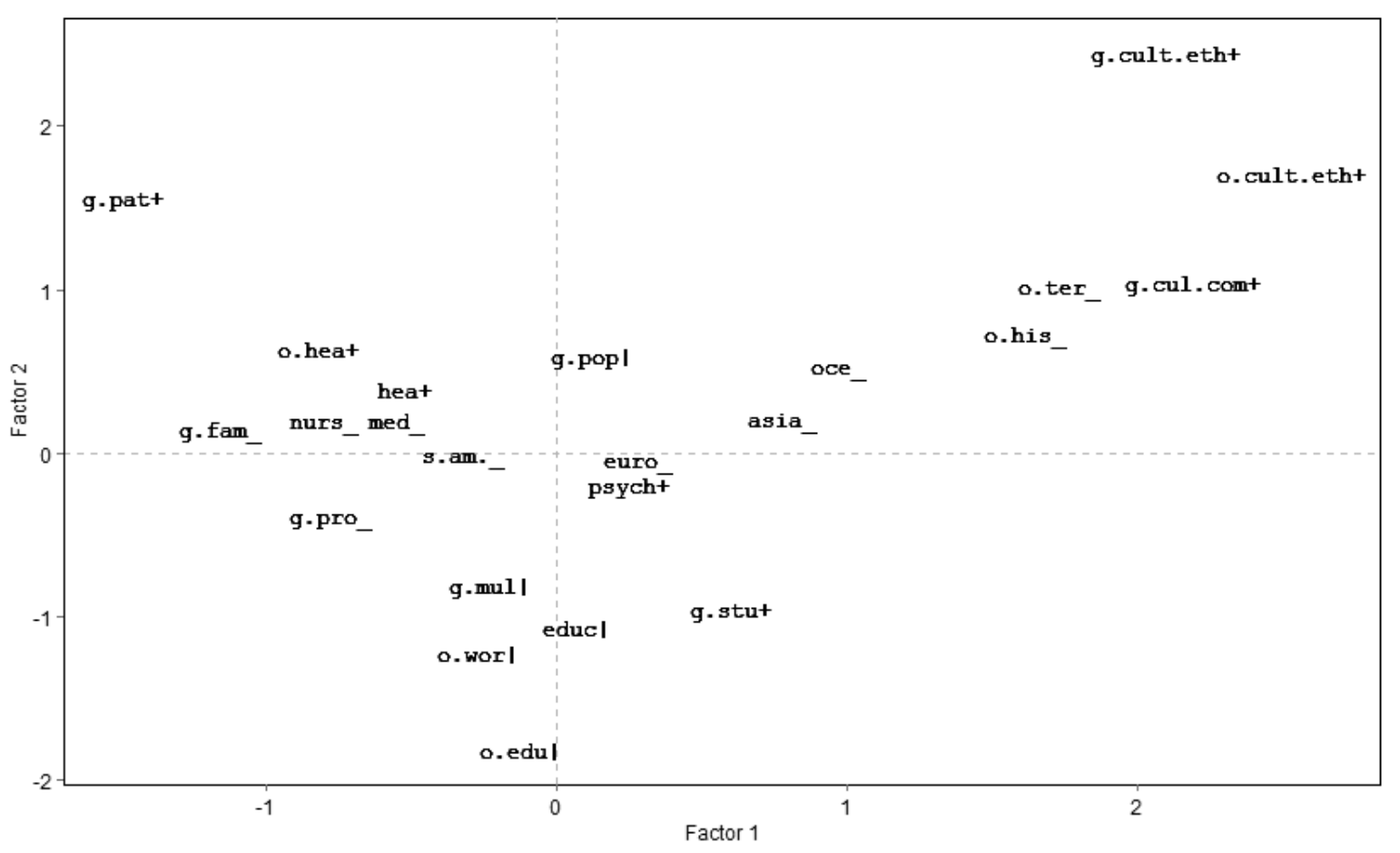

Figure 1. Multiple correspondence analysis based on the abstracts $\times$ group (g.) and object (o.) categories matrix.

Note. Continents: s.am. - South America; euro - Europe; oce - Oceania; asia - Asia. Objects: o.hea - health and well-being; o.wor - work; o.edu - education; o.cult.eth - culture and ethnicity; o.ter - territory and community; o.his - historic events. Groups: g.stu - students; g.pro - professions with specific formation; g.pop - general population; g.pat - patients; g.mul - multicategory; g.cult.com - cultural comparisons; g.fam - family members; g.cult.eth - ethnic groups. Journal disciplines: nurs - Nursing; med - Medicine; hea - Health; psych - Psychology; educ - Education. Significant contribution to factors: _: Factor 1 (horizontal axis); | : Factor 2 (vertical axis); + : Factors 1 and 2. Cum\%: cumulative percentages reflecting the represented proportions.

munity issues, as well as historical, cultural and ethnic topics. The privileged groups in terms of the comparison with the general sample profile are groups belonging to different culture realities, for territory, historical and cultural objects, and students of various levels. Research with such characteristics was more strongly associated with first author institution in Europe, Asia and Oceania, and corresponded to more publications in psychology. On the other hand, the applied pole focused on health-related objects and groups of professionals (doctors, nurses), family members and patients. A higher proportion of first authors aligned with those concerns is from South American institutions. The publication outlets in that case were health-related journals.

The second factor opposes research published about work and education objects with groups of students and multicategory affiliations to studies about social representations of health with groups of patients, and less pronouncedly with studies on culture or ethnicity with general population samples, and groups linked to culture and ethnicity. The axe region linked to education involves an association with publication in education journals, and less strongly with psychological journals, while the upper region is more associated with publication in health journals. The second factor can be interpreted as the opposition between applied education research, with specific interest in professional and formation realities, and a set comprising applied health research and some cultural-related research, associated with a more open-ended definition of groups and the relationship of patients with health and illness.

\section{Discussion}

The results of the content analysis of the journal paper abstracts published about social representations up to 2013 make it possible to 
identify a predominance of first authors located in the European and South American continent. Historically, the growth in proportion of authors from South American institutions is notable. At the national level, Brazil is currently the leader in terms of the location of first author, followed by France.

At this point, one might jump to the conclusion that South Americans, and especially Brazilians, are "taking over" the social representations ship. However, it must be noted that the results are restricted to the databases that were included in it. While we sought to consider generalist databases as well as some main ones related to the health, social and psychological fields, at the same time SciELO is a LatinAmerican-based database that might contribute to over-represent publications from that region from the 90s - it was created in 1997 - in our analysis (Packer et al., 1998). But arguably such over-representation might be a correction of a previous under-representation, as Latin American journals were less in number and visibility. The fact is that currently the number of journals from that region is much higher than in previous decades, and so is their representation in the major international databases (Alonso-Gamboa, \& Russell, 2012; Collazo-Reyes, 2014).

Anyhow, it is safe to conclude that the South American (and Brazilian) production on social representations published in scientific journals is very important. Perhaps it is no longer the case of referring so firmly to the social representations field as a "European" form of social psychology, or at least European-only. Our data make it look more like social representations might be getting Brazilian citizenship through "naturalization".

A closer look of the studied objects and groups reveals that the research carried out in both contexts is very different, though. There is a stronger-than-average association between European first authors and the study of cultural, ethnical, historical and territory issues with groups of students and members of different cultures or nations. Research of that kind tends to be more present in psychological journals. Research from authors linked to Oceania and Asia go in the same direction, with a variety of issues and groups of interest but with more emphasis than the general profile in terms of research linked to societal matters. In contrast, research led by South America-based authors is clearly applied to health issues. It can be observed in the results that health is a very important object for all of the investigated contexts, but it is more pronouncedly so in the Brazilian and South American ones. Such kind of research is mostly directed to the study of health professionals' and patients' representations of health related objects and mostly published in health-related journals.

The particularities of the research conducted in different geographic contexts have already been indicated in previous studies (Arruda, 2005; Camargo et al., 2007; De Rosa, 2013; Jodelet, 2011). Arguably, those differences might influence the development of the theory or the form that it takes. Jodelet (2011) assessed the Brazilian production on social representations and resisted to identify radical theoretical and methodological advances associated with it; on the other hand, she understands that Brazilian researchers combine the various contributions of European authors while at the same time providing a creative integration of classical approaches in order to shed light into practical problems that are relevant to regional contexts. Jodelet believes that the same pattern is found in other Latin American schools. Such interpretation does not consider a present or future change of direction in the development of social representations theory in global terms, but does not suggest passive incorporation either. Nevertheless, in-depth analysis of research and theory conducted in various contexts is needed to reach a more reliable diagnosis.

The second factor marks the peculiarity of education-related studies, usually published with teacher and student samples, contrasting to more general social psychological research and health studies and their corresponding group and object associations. The second factor is not associated with any specific continent, referring to broad oppositions in the field.

All in all, the results are in some ways an update of the previous inquiries done in the field, and in others they provide more refined 
and specific coverage of social representations research, as only journals are included. De Rosa and D'Ambrosio's (2008) highlighted a contrast of Europe-based research more related to theoretical questions and clearly aligned with paradigmatic forms of social representations theory with empirical and applied conference abstracts written by Latin American authors that referred to social representations generically. While our study did not identify paradigms or gave special attention to the addressed theoretical aspects and also restricted its scope to mostly empirical papers, a clear opposition was found in the correspondence analysis suggesting a stronger association of studied published in psychology journals concerning cultural and territory-related groups and objects, which probably indicate a stronger proportion of basic research dealing with theoretical properties of social representations than the South Americabased studies with groups and objects related to health. It must be noted, however, that objects related to the health sphere are dominant in the empirical studies in most continents and countries, even if they seem to be more so in South America, Brazil and Colombia. Most of Madiot's (2013) results related to International Conferences of Social Representations (ICSR) research are also reflected in journal production, with a strong importance of work, education and health objects and health and education professionals as groups of interest, a pattern that is found throughout the analyses presented here, even with slightly different categories.

Most of the results provided by De Rosa (2013) cannot be compared with the ones presented in this paper. De Rosa dealt mostly with an assessment of the theoretical framings of social representations in published pieces. Her category systems are also somewhat different regarding the themes of interest in the analyzed research. Still, a few important results found by the author have a parallel in our research: the thematic area of health-illness concerns an important proportion of $15 \%$, the highest outlining a specific class of objects. The overall proportion found in our study (31.1\%) includes only the abstracts with identifiable social objects; if the abstracts without such information were included, the proportion would be $20.6 \%$, which is closer to De Rosa's, even emphasizing the difference in terms of types of data sources covered by each study and category systems, as well as a noncoincidence in terms of the notion of thematic areas and social objects. Another pattern from De Rosa's results that was found in our study was the association involving Latin American studies and applied thematic areas.

It is important to point out that a considerable part of high level, developed contributions related to social representations research has not been considered by our analysis. Although the scope of the study involved mostly papers with identifiable groups and objects, it is clear that all contributions presented in the form of book chapters, empirical or theoretical, were not considered. How many are those? De Rosa's (2013) data bank of 2065 bibliographical sources had books chapters as the most frequent one, accounting for $46.2 \%$ of all sources; journal articles were responsible for $45.3 \%$. In addition, the presented study included some important databases, but they were restricted in number. So the reader should not have the understanding that the present analysis covers everything relevant ever published related to social representations; rather its goal was to provide a complete overview of relevant papers published in some databases. We cannot state that the found patterns would (or would not) be reproduced in the whole universe of scientific papers and other works. We acknowledge that important publications might have not been retrieved by our procedure, but at the same time we are confident that a significant part of the published and indexed production related to social representations could be obtained. With some over or underrepresentation justified by the databases that we chose, the picture that emerges from results is probably one that is faithful to social representations research reality. Of course, the production from conference proceedings and books has different characteristics and their inclusion or separate consideration would probably indicate different patterns. For instance, conference production might include more practical, applied research without sufficient innovation to be published in a journal; on the 
other hand, books might be privileged vehicles for theoretical discussion. Nevertheless, the analysis of journal production is probably the best course of action to assess the higher level of academic production in a field, due to the peer review process that is carried out, which unfortunately is not often the case in conferences and books.

However, regardless of the precision of the overview of journal publications related to social representations presented here and the knowledge entailed with it - discipline, continent and period preferences and priorities, group and objects associations - one issue that we cannot discuss properly with our data, but which is equally important, if not more, concerns the theoretical progress and the future of the field. A detailed and critical evaluation of what social representations theory has achieved and what it might still conquer in the understanding of knowledge and society is an absolute necessity. Such task cannot be postponed anymore, but cannot be advanced here. In terms of the relevance of the present study, it is out position that the success or pertinence of a theory or field of study is of course reflected in its diffusion and publication practices, and this contribution presents an overview of some of the related production. Hopefully, it can help the scientific community interested in social representations to understand what has been done up to this point, and serve as food for thought on discussions trying to explain the characteristics of the field and their consequences.

\section{References}

Abric, J.-C. (Ed.). (2003). Méthodes d'étude des représentations sociales. Toulouse, France: ERES.

Alonso-Gamboa, J. O., \& Russell, J. (2012). Latin American scholarly databases: A look back to the way forward. Aslib Proceedings, 64, 32-45. doi:10.1108/00012531211196693

Arruda, A. (1987). A Psicologia Social no nordeste nos anos 80: Levantamento de dados. Revista de Psicologia, 5, 73-85.

Arruda, A. (2005). Pesquisa em representações sociais: A produção em 2003. In M. S. S. Menin \& A. M. Shimizu (Eds.), Experiência e representa- ção social (pp. 59-92). São Paulo, SP: Casa do Psicólogo.

Camargo, B. V., Wachelke, J. F. R., \& Aguiar, A. (2007). Um panorama do desenvolvimento metodológico das pesquisas sobre representações sociais através de grupos de trabalho das jornadas internacionais. In A. S. P. Moreira \& B. V. Camargo (Eds.), Contribuições para a teoria e o método de estudo das representações sociais (pp. 181-202). João Pessoa, PB: Editora da Universidade Federal da Paraíba.

Collazo-Reyes, F. (2014). Growth of the number of indexed journals of Latin America and the Caribbean: The effect on the impact of each country. Scientometrics, 98, 197-209. doi:10.1007/ s11192-013-1036-2

De Rosa, A. S. (1992). Thematic perspectives and epistemic principles in developmental social cognition and social representation: The meaning of a developmental approach to the investigation of social representation. In M. von Cranach, W. Doise, \& G. Mugny (Eds.), Social representations and the social bases of knowledge (pp. 120-143). Lewiston, NY: Hogrefe and Huber.

De Rosa, A. S. (1993). Social representations and attitudes: Problems of coherence between the theoretical definition and procedure of research. Papers on Social Representations, 2, 178-192.

De Rosa, A. S. (2013). Research fields in social representations: Snapshot views from a meta-theoretical analysis. In A. S. De Rosa (Ed.), Social representations in the 'social arena' (pp. 89-124). London: Routledge.

De Rosa, A. S., \& D’Ambrosio, M. (2008). International conferences as interactive scientific media channels: The history of the social representations theory through the eight editions of ICSR from Ravello (1992) to Rome (2006) [Special issue]. Rassegna di Psicologia, 2, 161-207.

Durkheim, E. (1898). Représentations individuelles et représentations collectives. Sociologie et Philosophie. Paris: Presses Universitaires de France.

Duveen, G., \& De Rosa, A. S. (1992). Social representations and the genesis of social knowledge. Papers on Social Representations, 1, 94-108.

Farr, R. M. (1993). The theory of social representations: Whence and whither? Papers on Social Representations, 2, 130-138. 
Farr, R. M. (1996). The roots of modern social psychology: 1872-1954. Malden, MA: Blackwell.

Farr, R. M. (1998). From collective to social representations: Aller et retour. Culture and Psychology, 4, 275-296. doi:10.1177/1354067X9800400301

Greenacre, M. (2006). Tying up the loose ends in simple, multiple, joint correspondence analysis. In A. Rizzi \& M. Vichi (Eds.), Compstat 2006-Proceedings in Computational Statistics (pp. 163-185). Heidelberg, Germany: PhysicaVerlag HD. doi:10.1007/978-3-7908-1709-6_13

Greenacre, M. (2007). Correspondence analysis in practice ( $2^{\text {nd }}$ ed.). Boca Raton, FL: Chapman \& Hall. doi:10.1201/9781420011234

Husson, F., Lê, S., \& Pagès, J. (2011). Exploratory multivariate analysis by example using $R$. Boca Raton, FL: CRC.

Jesuíno, J. C. (2000). A Psicologia Social europeia. In J. Vala \& M. B. Monteiro (Eds.), Psicologia Social (4. ed., pp. 49-59). Lisboa, Portugal: Fundação Calouste Gulbenkian.

Jodelet, D. (1989). Représentations sociales: un domaine en expansion. In D. Jodelet (Ed.). Les représentations sociales (pp. 31-61). Paris: Presses Universitaires de France.

Jodelet, D. (2011). Ponto de vista: Sobre o movimento das representações sociais na comunidade científica brasileira. Temas em Psicologia, 19, 19-26.

Jodelet, D., \& Ohana, J. (1989). Bibliographie générale sur les représentations sociales. In $\mathrm{D}$. Jodelet (Ed.), Les représentations sociales (pp. 9-27). Paris: Presses Universitaires de France.

Le Roux, B., \& Rouanet, H. (2010). Multiple correspondence analysis. Los Angeles, CA: Sage. doi:10.4135/9781412993906

Lebart,L.,Morineau,A.,\&Piron,M.(1997).Statistique exploratoire multidimensionelle. Paris: Dunod.

Madiot, B. (2013). Analysing the French abstracts from the International Conferences of Social Representations. Papers on Social Representations, 22, 10.1-10.23.

Moreira, A. S. P., Camargo, B. V., Jesuíno, J. C., \& Nóbrega, S. M. (Eds.). (2005). Perspectivas teórico-metodológicas em representações sociais. João Pessoa, PB: Editora da Universidade Federal da Paraíba.

Moscovici, S. (1976). La psychanalyse, son image et son public. Paris: Presses Universitaires de France.
Moscovici, S. (1984). The phenomenon of social representations. In R. M. Farr \& S. Moscovici (Eds.), Social representations: Explorations in social psychology (pp. 3-69). Cambridge, UK: Cambridge University Press.

Moscovici, S. (1989). Des représentations collectives aux représentations sociales: élements pour une histoire. In D. Jodelet (Ed.), Les représentations sociales (pp. 62-86). Paris: Presses Universitaires de France.

Packer, A. L., Biojone, M. R., Antonio, I., Takenaka, R. M., García, A. P., Silva, A. C., ...Delbucio, H. C. R. F. (1998). SciELO: Uma metodologia para publicação eletrônica. Ciência da Informação, 27, 109-121. doi:10.1590/S010019651998000200002

R Core Team. (2013). R: A language and environment for statistical computing. Vienna, Austria: $\mathrm{R}$ Foundation for Statistical Computing. Retrieved from http://www.R-project.org/

Robette, N. (2014). GDAtools: A toolbox for the analysis of categorical data in social sciences, and specifically Geometric Data Analysis. R Package version 1.0. Retrieved from http://CRAN.Rproject.org/package $=$ GDAtools

Rouquette, M.-L. (1998). La communication sociale. Paris: Dunod.

Sá, C. P., \& Arruda, A. (2000). O estudo das representações sociais no Brasil [Número especial]. Revista de Ciências Humanas, 11-31.

Silva, A. M. F., Martini, J. G., \& Becker, S. G. (2011). A teoria das representações sociais nas dissertações e teses em Enfermagem: Um perfil bibliométrico. Texto e Contexto Enfermagem, 20, 294300. doi:10.1590/S0104-07072011000200011

Silva, S. E. D., Camargo, B. V., \& Padilha, M. I. (2011). A teoria das representações sociais nas pesquisas da Enfermagem brasileira. Revista Brasileira de Enfermagem, 64, 947-951. doi:10.1590/S0034-71672011000500022

Sousa, C. P. (2002). Estudos de representações sociais em Educação. Psicologia da Educação, 14/15, 285-323. 